
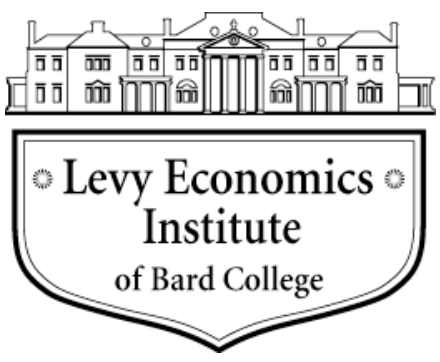

Working Paper No. 754

\title{
Growth Trends and Cycles in the American Postwar Period, with Implications for Policy
}

by

\author{
Olivier G. Giovannoni* \\ Bard College
}

February 2013

* Much of this paper was written while I was at the University of Texas at Austin, prior to joining the Bard College faculty in September 2010. I thank Thomas Ferguson, James K. Galbraith, Ric Holt, and Alain Parguez for their constructive comments. Some of the calculations have been performed with SVAR version 0.40 by Anders Warne, available at www.texlips.net/svar. All remaining errors are my sole responsibility. Comments welcome at ogiovann@bard.edu.

The Levy Economics Institute Working Paper Collection presents research in progress by Levy Institute scholars and conference participants. The purpose of the series is to disseminate ideas to and elicit comments from academics and professionals.

Levy Economics Institute of Bard College, founded in 1986, is a nonprofit, nonpartisan, independently funded research organization devoted to public service. Through scholarship and economic research it generates viable, effective public policy responses to important economic problems that profoundly affect the quality of life in the United States and abroad.

Levy Economics Institute

P.O. Box 5000

Annandale-on-Hudson, NY 12504-5000

http://www.levyinstitute.org

Copyright (C) Levy Economics Institute 2013 All rights reserved 


\begin{abstract}
Do all types of demand have the same effect on output? To answer this question, I estimate a cointegrated vector autoregressive (VAR) model of consumption, investment, and government spending on US data, 1955-2007. I find that: (1) economic growth can be decomposed into a short-run (transitory) cycle gravitating around a long-run (permanent) trend made of consumption shocks and government spending; (2) the estimated fluctuations are investment dominated, they coincide remarkably with the business cycle, and they are highly correlated with capacity utilization in both labor and capital; and (3) the long-run multipliers point to a large induced-investment phenomenon and to a smaller, but still significantly positive, government spending multiplier, around 1.5. The results cover a lot of theoretical ground: Paul Samuelson's accelerator principle, John Kenneth Galbraith's stress on consumption and government spending, Jan Tinbergen's investment-driven business cycle, and Robert Eisner's inquiries on the investment function. The results are particularly useful to distinguish between economic policies for the short and long runs, albeit no attempt is made at this point to inquire into the effectiveness of specific economic policies.
\end{abstract}

Keywords: Economic Growth; Cointegration; Accelerator; Business Cycle; Multipliers; Economic Policy

JEL Classifications: C3, E2 


\section{INTRODUCTION}

Do all types of demand matter equally for economic growth? To answer this question, I set up an empirical study of growth where production is defined by the components of the identity $Y \equiv$ $C+I+G$. I then study the dynamics of consumption, investment, and government spending through the lens of the feature-rich and "agnostic" cointegrated vector autoregressive (VAR) model (Johansen 1996; King, Plosser, Stock, and Watson 1991). I address the following questions: In the determination of output, do all types of spending matter equally? Do they have the same roles? Is there a more empirically relevant theory of growth?

This paper shows that a rich modeling framework leads to the distinction between the variables explaining either the cycle or the trend, so that economic policy should target specific and different aggregates if the goal is a short-run or long-run one. The present inquiry is of further importance in the context of the Great Recession, which has revived many debates on the scale and efficiency of economic policies. In this respect, the model also yields interesting insights into the old issues of the accelerator and the multiplier. All in all, we conclude that the model provides empirical evidence in support of an encompassing Keynesian view of the economy.

\section{Theories}

The literature on economic growth provides a useful context for our analysis. Because this is quite possibly the largest body of literature in economics, we will need a classification scheme. While acknowledging the limitations of all classification schemes, it is fair to say that the current state of knowledge on growth can be seen as consisting of three major strands. The first two are theoretical: we will show that a respected consensus emerges, but a set of important developments sits uncomfortably next to this consensus. The third strand consists of what we have learned from empirical investigations.

The well-defined and respected consensus generally ascribes growth to investment with growth being pegged, one way or another and mostly over the long run, to the dynamics of investment (see, for instance, Solow 1956, Somer 1957, and Romer 1986). Investment is also at the core of much of the Keynesian growth literature with the presumption that in order to understand growth, one must first understand the determinants of investment-money, credit and/or finance, expectations, consumption demand, and economic policy, to name a few. 
Following John Kenneth Galbraith, I shall refer to this general consensus as "the investment-led conventional wisdom." But if growth is indeed investment-led, what are the roles of the other growth components in $Y \equiv C+I+G$ ?

Next to the conventional wisdom lies, in fact, a set of well-established theories, or models, concerned about the roles of consumption and government spending. The role of the latter is possibly the most easily grasped. Government action is needed in the presence of externalities, in cases of market failures, for strategic reasons, or quite possibly to stimulate activity ("pump priming"). Although the contours and the form of public action can be ambiguous, and although much controversy remains, we have learned that government spending can benefit growth in those cases.

The most interesting question raised by growth theory appears to be, however, how consumption is treated in this framework. A short list of well-known consumption theories includes the underconsumptionist approach, the consumption chapters in Keynes (1936), the principle of acceleration as stated in Samuelson (1939a, b), the permanent income hypothesis of Friedman (1957), and the consumption excesses of Galbraith (1958) — not to mention the works in those traditions. In common, all of these theories are well respected, have been influential, and grant consumption a positive and active role through, respectively, its absence, its degree of exogeneity, its smoothness, or its general importance in our affluent economies. Are we then to believe that growth is consumption-led or investment-led?

\section{Empirical studies}

Empirical studies have shed some light on those questions. A first simple way of dealing with the relative importance of consumption and investment is to look at what the data says. Figure 1 presents the historical record for the "contributions to percent change in real gross domestic product" as featured in national income and product accounts (NIPA), Table 1.1.2. Because of the volatility of quarterly observations, the data has been smoothed by a moving average over 12 quarters. 
Figure 1 Contribution to changes in real gross domestic product

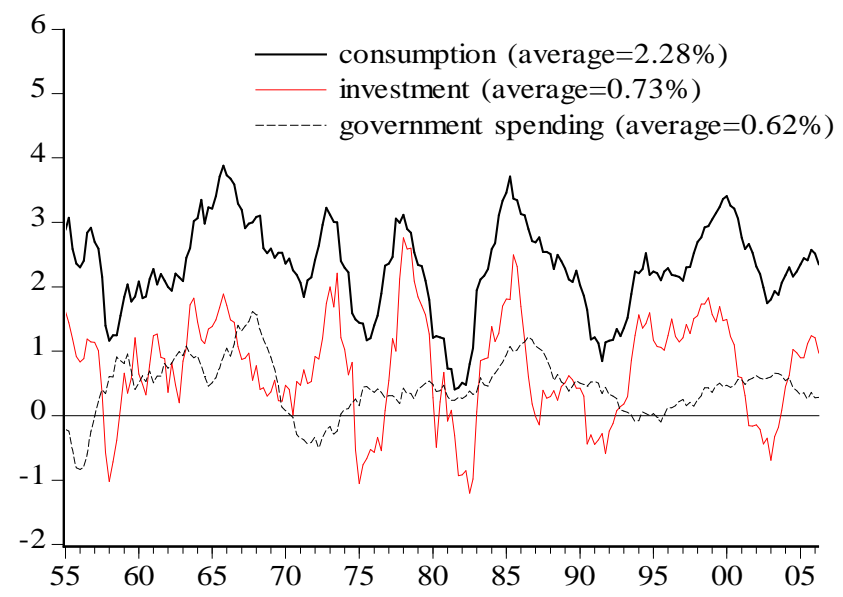

Source: NIPA revision 2003, Table 1.1.2. 3-year moving averages

Figure 1 shows that, for the period 1955q1-2006q2, the contribution of consumption to growth is most of the time greater than the contribution of investment by a margin of +1.6 percent. Not only is the contribution of consumption to GDP larger, it also happens more often: the contribution of consumption is superior to that of investment in three cases out of four. The average spread in that case is of +2.8 percent and only +1.8 percent in the one case of a greater investment contribution. As such, this preliminary empirical study seems to provide greater support to the theoretical consumption-led hypothesis. However, the importance of the questions at hand calls for a data analysis deeper than the description above. In particular, it seems crucial to set the question in terms of dynamics ("what drives growth?"), rather than what accounts for realized growth.

A good amount of econometric studies have shed some light on the investment-led versus consumption-led theories. Those, in turn, fall into two categories. The first one is that originating most notably in Tinbergen's $(1938,1939)$ early econometric studies. Those studies provided support for investment-led short-run fluctuations as well as for the accelerator principle (Eisner 1978). However, there is a limitation to those pioneering works: they suffer from "early econometric modeling" when we did not have the methods distinguishing between short-run and the long-run effects. Does the investment business cycle paint a short-run picture only, and if so, what is the cycle around?

This question was more or less explicitly answered in the early 1990s by the second category of empirical studies, which uses more recent econometric techniques. In a classic article, King et al. (1991) use the particularly rich structure of the cointegrated VAR model to 
study private GNP, consumption, and investment in the US economy over the period 19491988. The authors find that consumption leaves permanent shocks so that (cumulated) consumption shocks define the long-run trend of the economy. ${ }^{1}$ To the contrary, investment and output are found to have an adjusting behavior to the trend, in the sense that investment and output shocks are merely transitory. Those results have been investigated by different authors with different models and different methods with the original results being confirmed. ${ }^{2}$

King et al. (1991) interpret this finding alongside the real business cycles theory by treating consumption shocks as evidence of productivity improvements. Fisher, Huh, and Tallman (2003) point to this result as stemming from a particular interpretation of the shocks and carry on providing another interpretation. The idea now is that consumption can only be permanent if it comes from a permanent income-which leads to Friedman (1957), who ascribes permanent income to increases in total factor productivity. Thus, the bottom line of King et al. (1991) and Fisher, Huh, and Tallman (2003) is the same: growth originates from (unobservable) productivity shocks. Investment and output adjust passively.

\section{Questions}

The present paper builds on those empirical studies and introduces three major changes. Our first task will be to extend the model to investigate the role of government spending. The literature above did not incorporate the second largest component of GDP, with the conclusion that the fate of GDP is left to the behavior of the private sector. The second task relates to the uneasy finding that the trend of the American economy consists of consumption shocks alone. That consumption has a role to play in the determination of economic growth should be obvious, but discarding the role of investment to that of a passively adjusting variable is another: doesn't investment have a role to play, too? Which one? Third, and finally, we need to reassess the empirical model to check where it fits in the theoretical literature, if at all. In particular, it will be interesting to see if the model, now including government spending, still supports a productivity/real business cycles interpretation à la King et al. (1991).

The rest of the paper is organized as follows. Section 2 presents the data and the cointegrated VAR model method, while Section 3 focuses on its specification. The subsequent

\footnotetext{
${ }^{1}$ Throughout the rest of the paper, we will follow the existing econometric literature and refer to "shocks" when dealing with the residuals of the estimated model.

${ }^{2}$ See Fama (1992) and Blanchard (1993) for the case of the 1990-91 recession, Cochrane (1994) for consumption of nondurables only, and Fisher, Huh, and Tallman (2003) for a modernized approach (and an updated sample) to the questions raised by King et al. (1991).
} 
two sections present econometric evidence for the role and nature of investment: the business cycle (Section 4) and causality (Section 5). Section 6 provides a reassessment in terms of economic theory and policy.

\section{DATA PROPERTIES AND THE RELEVANCE OF THE COINTEGRATED VAR MODEL}

Our first goal is to let the data speak freely and re-interpret the findings alongside the economic literature. The advantage is that we do choose the model's variables based on theoretical assumptions-which are often untested or controversial (Sims 1980; Juselius 2006). On the contrary, our starting point is that economic growth is actually given by the behavior of consumption, investment, and government spending:

$$
Y_{t} \equiv C_{t}+I_{t}+G_{t}
$$

Note that we are here studying $Y_{t}$, the gross domestic purchases, which the NIPA defines as GDP minus the trade balance (but includes changes in inventories). It will be shown that the case of a closed economy is already interesting in itself, while the influence of imports and exports is left to a further analysis. Note, also, that our growth variable $Y_{t}$ is exactly determined by the three variables of the accounting identity above; in this sense the model is exactly specified and there is no missing or redundant variable, which, had it been accounted for or discarded, would have changed the econometric results. Since the right hand side $i s$ production, we will not use a gross domestic purchases variable to avoid redundancy. ${ }^{3}$

The data for consumption, investment, and government spending is taken from the NIPA Revision 2003, Table 1.1.6. Each variable is specified in billions of chained 2000 dollars, is seasonally adjusted, and is taken in logarithms. The data runs from 1955q1 to 2007q4 ( $T=212$ observations). The current Great Recession is better left out of the sample-for not only is it an outlier, but an outlier at the end of the sample, which is never a good thing to have. Figure 2 presents the data in levels and first differences. ${ }^{4}$

\footnotetext{
${ }^{3}$ This redundancy problem arises in King et al. (1991), for instance, who estimate regressions on the whole (GNP) on some of its parts. The gross domestic purchases aggregate is a statistical construct in itself (a summation), rather than a properly stochastic variable.

${ }^{4}$ The NIPA data is available from 1947 on a quarterly basis, but we discarded the information prior to 1955 due to the accumulation of destabilizing events such as the Korean War, the Treasury-Fed Accord, and general volatility of the era, even in real terms.
} 
Figure 2 Plot of the variables (log-levels and log-changes)
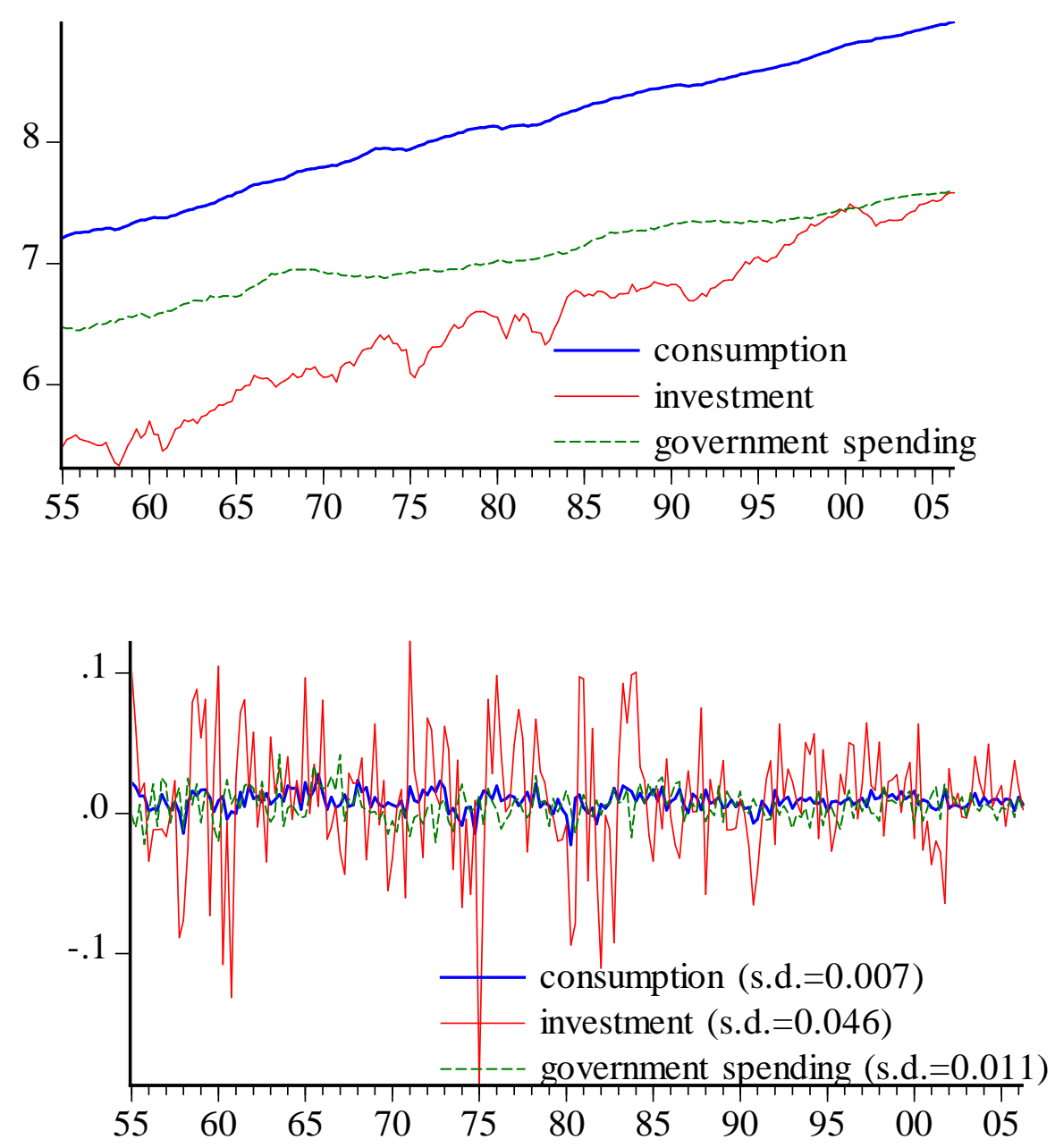

Source: NIPA revision 2003, table 1.1.6. Logarithms of 2000 billion Dollars.

The graph of the data in differences shows the much greater volatility of investment as compared to consumption and government spending. The data in levels shows again a great amount of volatility in investment, but its overall trend is linear. ${ }^{5}$ Figure 2 also shows smoothly evolving trends in each variable, which is characteristic of unit roots processes. Most importantly, investment and consumption exhibit co-movements over the long run, isolating government spending as growing at a slower pace, mostly since the early 1970s.

Johansen $(1988,1991,1992,1996)$ and Johansen and Juselius $(1990,1992)$ have popularized the use of error correction models for modeling unit root processes with co-

\footnotetext{
${ }^{5}$ An interesting finding is that American real investment turns out trend-stationary on the 1955-2006 period, and very significantly so (below the 5-percent level with the usual unit root tests).
} 
movements, such as is the case of the data here. Those models are also known as cointegrated VAR models because they rest on two major econometric advances, the VAR model and cointegration analysis.

Cointegration analysis, a field pioneered in Engle and Granger (1987), is interested in the co-movements in time of non-stationary variables. Cointegration implies (1) that a certain causal chain relates the variables; (2) that the non-stationary variables are driven by the same persistent stochastic shocks, which are attributable to one or several variables in the model; and (3) that one can isolate a long-run structure from short-run movements-indeed a desirable property in an analysis of growth trends and cycles.

VAR models allow modeling dynamic interactions in a system framework of simultaneous equations. Johansen's approach to error correction models is based on the reduced-form VAR model with $k$ lags

$$
X_{t}=\Pi_{1} X_{t-1}+\ldots+\Pi_{k} X_{t-k}+\Phi D_{t}+\mu+v_{t}
$$

where $X_{t}$ is the set of $p$ variables of interest, $D_{t}$ and $\mu$ are vectors of deterministic variables and constants, respectively, and the $\Pi_{i} \mathrm{~s}$ and $\Phi$ are matrices of freely estimated coefficients.

Provided that the error terms are Gaussian ${ }^{6}$, equation (1) can alternatively be rewritten in its error correction form (Johansen 1996):

$$
\Delta X_{t}=\alpha \underbrace{\beta^{\prime} X_{t-1}}_{\text {long run }}+\underbrace{\sum_{i=1}^{k-1} \Gamma_{i} \Delta X_{t-i}}_{\text {short run }}+\underbrace{\tilde{\Phi} D_{t}+\mu_{0}+\mu_{1} t}_{\text {deterministics }}+\underbrace{\varepsilon_{t}}_{\text {error }}
$$

where $\Gamma_{i}=-\sum_{j=i+1}^{k} \Pi_{j}$ and $\Pi=\sum_{i=1}^{k}\left(\Pi_{i}-\mathrm{I}_{\mathrm{p}}\right), \mathrm{I}_{\mathrm{p}}$ being the identity matrix. For the sake of generality, we allow for the possibility that the deterministic components $\mu_{0}=\alpha \beta_{0}+\gamma_{0}$ (constant) and $\mu_{1}=\alpha \beta_{1}+\gamma_{1}$ (trend) enter the cointegrating relationship. Note that the error correction representation supposes that $\alpha \beta^{\prime}$ has a reduced rank such as $1 \leq r k\left(\alpha \beta^{\prime}\right)<p$, or else equation (2) would be misspecified.

\footnotetext{
${ }^{6}$ Gaussian errors are independently, identically, and normally distributed errors by definition, and have mean zero by construction. This is required for effective cointegration testing. Note that $v_{t}:=X_{t}-E_{t-1}\left(X_{t} \mid X_{t-1}, \ldots, X_{t-n}\right)$ when the errors are Gaussian. In that case, the model rests upon the rational expectation hypothesis, provided that $E_{t-1}\left(X_{t} \mid X_{t-1}, \ldots, X_{t-n}\right)$ is the actual way that agents form their expectations.
} 
The rank $r=r k\left(\alpha \beta^{\prime}\right)$ has decisive implications since it splits the data into $r$ stationary directions (the long-run cointegrating relationships, or "steady-states") and $p-r$ non-stationary directions (the unit roots or "common trends" of the model). The stationary and non-stationary directions clearly separate a long-run structure from a short-run structure within the cointegrated VAR model. This is better seen on the moving average form (3): ${ }^{7}$

$$
X_{t}=\underbrace{\mathrm{C} \sum \varepsilon_{i}+\mathrm{C} \mu t}_{\begin{array}{c}
\text { non stationary part (trend) } \\
\text { stochastics and deterministics }
\end{array}}+\underbrace{\mathrm{C}^{*}(L) \varepsilon_{t}}_{\begin{array}{c}
\text { stationary part } \\
\text { (cycle) }
\end{array}}+\underbrace{\tilde{\mathrm{X}}_{0}}_{\text {initial values }}
$$

where $\mathrm{C}=\beta_{\perp}\left(\alpha_{\perp}^{\prime} \Gamma \beta_{\perp}\right)^{-1} \alpha_{\perp}^{\prime}$ is the long-run impact matrix of shocks. Note that the long run/short run dichotomy in (2) translates into a trend/cycle decomposition in (3), à la Beveridge and Nelson (1981).

As advocated by Sims (1980), a major advantage of VAR models is that they do not attribute endogenous or exogenous roles to the model's variables on an a priori or theoretical basis. Cointegrated VARs are particularly well suited to the case of non-stationary variables like the ones under study. In particular, those models rest upon a rich, most general structure in which all statistical tests are performed coherently in the same framework. Specification, estimation, and identification of the model can be made on the basis of such statistical tests.

\section{SPECIFICATION, STRUCTURAL TESTS, AND STABILITY}

The price to pay for the model's generality is that error correction models need to be specified very carefully (Johansen 1996, Juselius 2006). Some specification tests rest on non-standard inferences, while others are interdependent. To overcome those difficulties, we estimated the model using the specification procedure presented in the Appendix. The procedure resulted in a model (see equation 1) with a lag length $k=2$ and seven dummy variables capturing extraordinary, exogenous events (listed in the Appendix). Table 1 presents the results of the specification tests for the period 1955q1-2007q4 (Part A).

\footnotetext{
${ }^{7}$ The common trends representation depends on the deterministic part of the model. It is here written in the case of an unrestricted constant (Johansen's case 3, see below).
} 
Table 1 Specification of the model

Part A: Residual specification for the VAR(2) model

\begin{tabular}{|c|c|c|c|c|c|c|}
\hline & \multicolumn{2}{|c|}{ 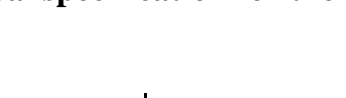 } & \multicolumn{3}{|c|}{$\begin{array}{c}\text { Joint system-wide } \\
\text { normality }\end{array}$} & \multirow{2}{*}{$\begin{array}{c}\text { Individual } \\
\text { normality in } \\
\log C / \log I / \log G\end{array}$} \\
\hline & $\begin{array}{l}\operatorname{LM}(1) \\
\operatorname{LM}(2)\end{array}$ & $\begin{array}{l}\text { VARCH(1) } \\
\text { VARCH(2) }\end{array}$ & skew & kurt & joint & \\
\hline No dummy & $\begin{array}{l}0.15 \\
0.23\end{array}$ & $\begin{array}{l}0.01 \\
0.10\end{array}$ & 0.00 & 0.07 & 0.00 & $0.00 / 0.00 / 0.09$ \\
\hline 7 dummies & $\begin{array}{l}0.44 \\
0.28\end{array}$ & $\begin{array}{l}0.01 \\
0.09\end{array}$ & 0.91 & 0.00 & 0.01 & $0.19 / 0.00 / 0.91$ \\
\hline
\end{tabular}

Part B: Cointegration tests

\begin{tabular}{|c|c|c|c|c|c|c|}
\hline & \multicolumn{3}{|c|}{ Type 4 - const. and restr. trend } & \multicolumn{3}{|c|}{ Type 3 - unrestricted constant } \\
\hline & $\begin{array}{c}\text { Largest } \\
\text { non unit } \\
\text { root }\end{array}$ & $\begin{array}{c}\text { Johansen } \\
\text { Trace } \\
\text { p-value }\end{array}$ & $\begin{array}{c}\text { S\&L } \\
\text { p-value }\end{array}$ & $\begin{array}{c}\text { Largest } \\
\text { non unit } \\
\text { root }\end{array}$ & $\begin{array}{c}\text { Johansen } \\
\text { Trace } \\
\text { p-value }\end{array}$ & $\begin{array}{c}\mathrm{S} \& \mathrm{~L} \\
\text { p-value }\end{array}$ \\
\hline$r=0$ & 0.37 & 0.03 & 0.02 & 0.37 & 0.00 & 0.00 \\
\hline$r=1$ & 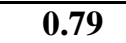 & 0.71 & 0.66 & 0.79 & 0.46 & \begin{tabular}{|c|}
0.34 \\
\end{tabular} \\
\hline \multirow[t]{2}{*}{$r=2$} & 0.96 & 0.51 & 0.42 & 0.96 & 0.31 & n.a. \\
\hline & \multicolumn{3}{|c|}{$p^{L R}\left(\gamma_{1}=0 \mid r=1\right)=0.72$} & \multicolumn{3}{|c|}{$p^{L R}\left(\mu_{0}=\alpha \beta_{0} \mid r=1\right)=0.00$} \\
\hline
\end{tabular}

Note: Statistics reported are the test probabilities.The Trace test is that of Johansen (2002) using a Bartlett small sample size adjustment. S\&L stands for the Saikkonen and Lütkepohl (2000a, b, and c) test.

Table 1 shows that our model is sufficiently well specified; most importantly, residual autocorrelation is decisively rejected. The residuals are not jointly normally distributed, but the source of non-normality is clearly identified as stemming from excess kurtosis in investment only. This should come as no surprise as investment is known to be highly volatile, especially around turning points. Because non-normality originates from localized excess kurtosis as opposed to excess skewness, inference should not be compromised to a considerable extent (Juselius 2006).

Now that the model has satisfying properties, the analysis of cointegration structure can begin. Given the limitations of cointegration tests, two of such tests have been performed: the Johansen (2002) Trace test and the Saikkonen and Lütkepohl (2000a, b, and c) test. The results of both tests, presented in Table 1, Part B, overwhelmingly indicate the presence of a single cointegrating relationship. A model with constant but no trend in the cointegrating relationship was chosen on the basis of a likelihood ratio test ${ }^{8}$ and, in this context, the rank choice $r=1$ is

\footnotetext{
${ }^{8}$ Because all cointegration types are nested into one another, the choice of a particular type of cointegrating relationship can be made on the basis of the significance of the extra deterministic term. A likelihood ratio test on a type-4 model strongly rejects the presence of a trend in the autoregressive part $\left(p^{L R}\left(\gamma_{1}=0\right)=0.72\right)$. The same test performed in a case 3 model could not reject the presence of a constant $\left(p^{L R}\left(\gamma_{0}=0\right)=0.00\right)$.
} 
stable across the sample (see Johansen 1996, Hansen and Johansen 1999, and Figure A1 in the Appendix).

The estimated cointegrating relationship is presented in Table 2. However, the model is still unrestricted and our understanding would greatly benefit from imposing testable overidentifying restrictions. The purpose of this exercise is to identify a structure in the model that is both theoretically meaningful and empirically supported by the data (Juselius 2006). Two important restrictions come to mind in the present context: a restriction of the long-run parameters $\beta$ and restrictions of the adjustment coefficients $\alpha$.

The unrestricted cointegration relation presents estimated $\beta$ coefficients almost summing to zero. This would mean that the (long-run) elasticities of production (real gross domestic purchases) with respect to consumption, investment, and government spending sum to unitywhich is a property the data should verify. Thus, we formulate restriction $H_{l}: \hat{\beta}_{\mathrm{C}}+\hat{\beta}_{\mathrm{I}}+\hat{\beta}_{\mathrm{G}}=0$ (with an arbitrary normalization of -1 on the consumption coefficient).

The second important structural test pertains to the significance of the adjustment coefficients. If $H_{2 i}: \hat{\alpha}_{i}=0$ is verified, variable $i$ is said to be weakly exogenous with respect to the long-run parameters $\beta$ (Johansen 1996). In this case, the cumulated shocks to the weakly exogenous variable define a common stochastic trend in the system. An interesting scenario takes place when the number of weakly exogenous variables matches the number of variables minus the rank $(m=p-r)$ : in this case, all the non-stationary directions of the process are defined by the (cumulated shocks to the) weakly exogenous variables (the permanent shocks). At the same time, the $r$ non-weakly exogenous variables would only have transitory effects, that is, they would define a purely cyclical component. Thus, the weak exogeneity test is crucial to the distinction between variables leaving permanent effects and those leaving only transitory shocks.

Table 2, Part A presents the results of those two structural tests. Hypothesis $H_{l}$ : $\hat{\beta}_{\mathrm{C}}+\hat{\beta}_{\mathrm{I}}+\hat{\beta}_{\mathrm{G}}=0$ cannot be rejected at the 66 percent level, while the weak exogeneity hypothesis $H_{2 i}$ cannot be rejected for consumption and government spending (only borderline so for 
consumption). ${ }^{9}$ The final, restricted model is given in Table 2, Part B (see Table A4 in the Appendix for the point-estimates of the dummy variables).

Table 2 Cointegration relations and structural tests

Part A: Restriction tests

\begin{tabular}{|c|c|}
\hline \multicolumn{2}{|c|}{$\begin{array}{l}H_{I}: \text { unit sum of elasticities with respect to gross domestic purchases* } \\
p^{L R}\left(\hat{\beta}_{C}+\hat{\beta}_{I}+\hat{\beta}_{G}=0\right)=0.66 \quad[0.19]\end{array}$} \\
\hline 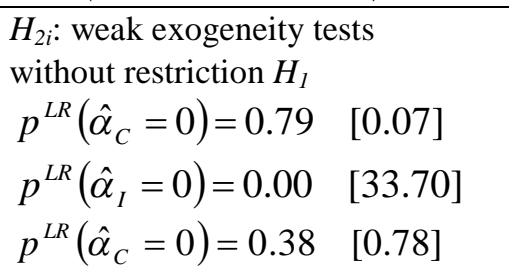 & $\begin{array}{l}\text { with restriction } H_{I} \\
p^{L R}\left(\hat{\alpha}_{C}=0\right)=0.84 \\
p^{L R}\left(\hat{\alpha}_{I}=0\right)=0.00 \\
p^{L R}\left(\hat{\alpha}_{C}=0\right)=0.29 \quad[133.51] \\
\end{array}$ \\
\hline $\begin{array}{l}\text { Joint test of } H_{1}, H_{2 C}, H_{2 G} *: \\
p^{L R}\left(\hat{\beta}_{C}+\hat{\beta}_{I}+\hat{\beta}_{G}=0, \hat{\alpha}_{\mathrm{C}}=0\right.\end{array}$ & $0)=0.80$ \\
\hline
\end{tabular}

Note: the statistics reported are the tests probabilities, while those in brackets are the empirical values of a likelihood ratio test.

* Using a Bartlett small-sample size adjustment

\section{Part B: Restricted and Unrestricted cointegration relations}

Unrestricted: $\hat{u}^{M L}: \quad \underset{\{0.00\}}{1.00^{*}} \log C_{t-1}-\underset{\{0.00\}}{0.63^{*}} \log I_{t-1}-\underset{\{0.04\}}{0.40^{*}} \log G_{t-1}-1.21$

Restricted: $\quad \hat{u}_{\text {restr. }}^{M L}: \underset{\{0.00\}}{-1.00 *} \log C_{t-1}+\underset{\{0.00\}}{0.66 *} \log I_{t-1}+\underset{\{0.00\}}{0.34 *} \log G_{t-1}-1.21$

with

$$
\left\{\begin{array} { l } 
{ \hat { \alpha } _ { C } = \hat { \alpha } _ { G } = 0 } \\
{ \hat { \alpha } _ { I } = - \underset { [ 6 . 0 7 ] } { 0 . 2 6 } }
\end{array} \quad \left\{\begin{array}{l}
p_{\operatorname{restr}(\alpha, \beta)}^{\mathrm{LR}}=0.80 \\
\log L=1891.59 \\
\text { largest non }- \text { unit root }=0.77
\end{array}\right.\right.
$$

Note: Coefficients in accolades represent the $p$-values of a likelihood ratio exclusion test.

The econometric specification is now complete. The model for consumption, investment, and government spending is correctly specified with $r=1$ restricted cointegrating relationship. For comparative purposes, King et al. (1991) as well as Fisher, Huh, and Tallman (2003) find two cointegrating relationships $(r=2)$, which are left unrestricted. Both studies use a model with a trend in the cointegration relationships and the significance and meaning of that trend is not discussed. However, our results coincide with those two studies on the weak exogeneity of consumption and the strong endogeneity of investment.

\footnotetext{
${ }^{9}$ Together, those three hypotheses $H_{l}, H_{2 C}$, and $H_{2 G}$, could not be rejected at the 80-percent level, far from any conventional value (statistics using a Bartlett small-sample correction factor).
} 
Most importantly, our model presents quite a different structure. Since $p-r=2=m$, the permanent component of growth (the common trend) is identified as stemming from consumption shocks and government spending shocks, with investment shocks having only transitory (short-run) effects. This means that, in the period 1955-2007, growth in the US can be intuitively represented in the following way: consumption and government spending are the combined forces that make up the growth trend, while investment has been responsible for the fluctuations around this trend.

The theoretical interpretation of the results is reserved for our reappraisal in Section 6. For now, we need to inquire more deeply into the enigmatic transitory nature of investment shocks - an issue neglected in the literature above. Looking at the investment equation, we find that investment is strongly and significantly affected by two major forces: the cointegrating relationship and consumption. We address those two factors, in turn, in the following sections.

\section{A CAPACITY/BUSINESS CYCLE INDICATOR}

The first point is that investment follows the dynamics of the cointegration relationship. By construction, $\hat{u}^{M L}$ is a stationary variable describing the cyclical departures from the linear, long-run relationship. We are going to show that those departures are more than an "error term"- the way those departures are usually treated. In our model of consumption, investment, and government spending, the long-run relationship represents the average long-run growth path. Thus, the fluctuations $\hat{u}^{M L}$ represent cyclical deviations from the long-run growth path. Could the short-run fluctuations $\hat{u}^{M L}$ capture the business cycle, in the Tinbergen $(1938,1939)$ spirit? 
Figure 3 The cointegrating "business cycle" relationship

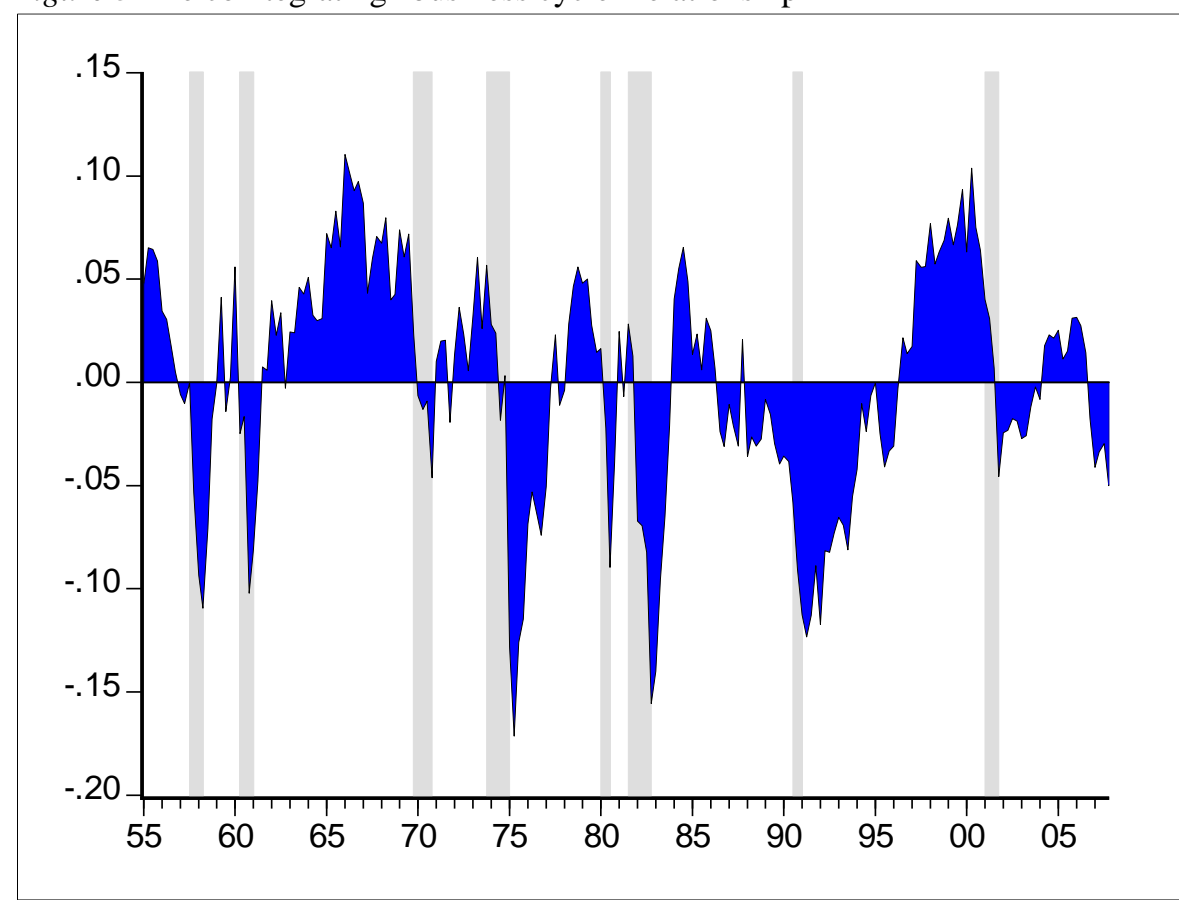

Note: Fully restricted model. Shaded areas represent recessions as dated by the NBER.

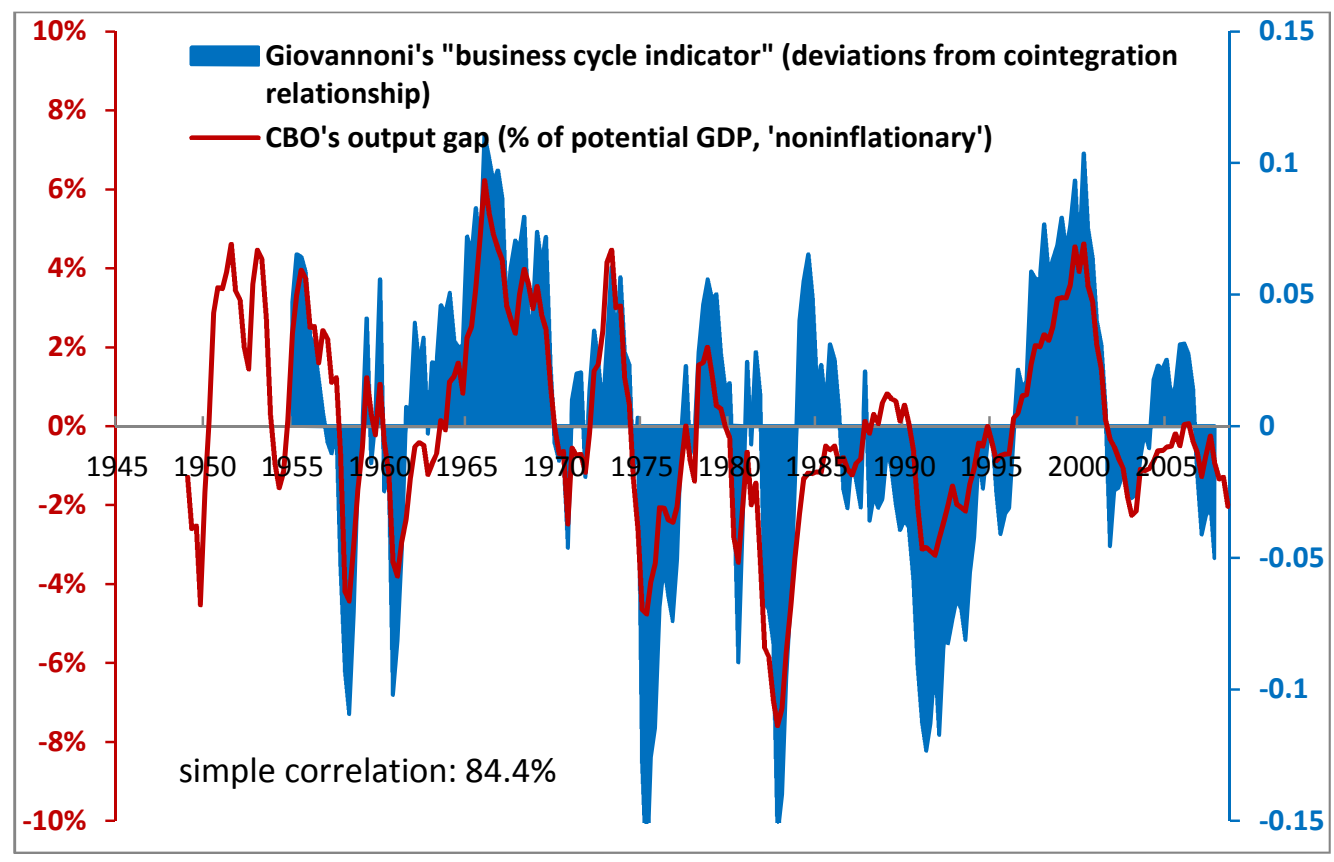

Note: CBO's potential GDP is estimated using a + Okun relationship + Philips/NAIRU model.

Source: Author's calculations based on CBO "The Budget and Economic Outlook," various years. 
Figure 3 presents the restricted cointegrating relationship. The graph reveals, indeed, a striking correlation with the typical booms and busts of economic activity. Expansions are well represented above the zero line and contractions below; the magnitude of the swings matches common knowledge, by and large, with the largest recessions taking place in 1974 and 1982, while the largest expansions take place in the 1960s and late 1990s. The turning points and phase durations are a close match to the NBER calls. More specific historical events are also well represented, such as the great variability of the late 1950s, the short expansion of 1981, the stock market crash of 1987, and the brief slowdown of 1995. The correlation is not perfect: there is an underestimation of the business cycle during the 1985-1995 decade, and an overemphasis of the 1990 recession. But aside from that, the cointegrating relationship $\hat{u}^{M L}$ is a very close estimate of the business cycle. The closeness of the match is such that it gives the estimated cointegrating relationship a potentially important forecasting content.

Can we test Tinbergen's proposition of investment-driven economic cycles? In a way, we already found evidence in that direction since the business cycle indicator and investment are closely related (not consumption, not government spending). We can provide further evidence by performing an impulse-response analysis: we simulate "typical impulses" (shocks of one standard deviation) to the estimated system and see how the cointegration relationship responds. Such responses are presented on Figure 4, top panel. Indeed, the cointegrating relationship reacts mostly to investment, but consumption also plays a significant role_-about half as important as investment. Interestingly, typical government spending shocks are not found to affect business cycles, at least when business cycles are understood as the cointegrating relationship. ${ }^{10}$

\footnotetext{
${ }^{10}$ One explanation may lie in distinguishing between the structural from the cyclical part of government spending. The finding that business cycles are government spending-neutral means that government spending is better thought of as consisting mostly of structural outlays, i.e., "routine" or "long-run" types of outlays. This explanation matches the exogenous nature of government spending previously documented.
} 
Figure 4 Response functions

Part A: Response of $\hat{u}_{t-1}^{M L}$ to model-based impulses in $C$, I, and $\boldsymbol{G}$
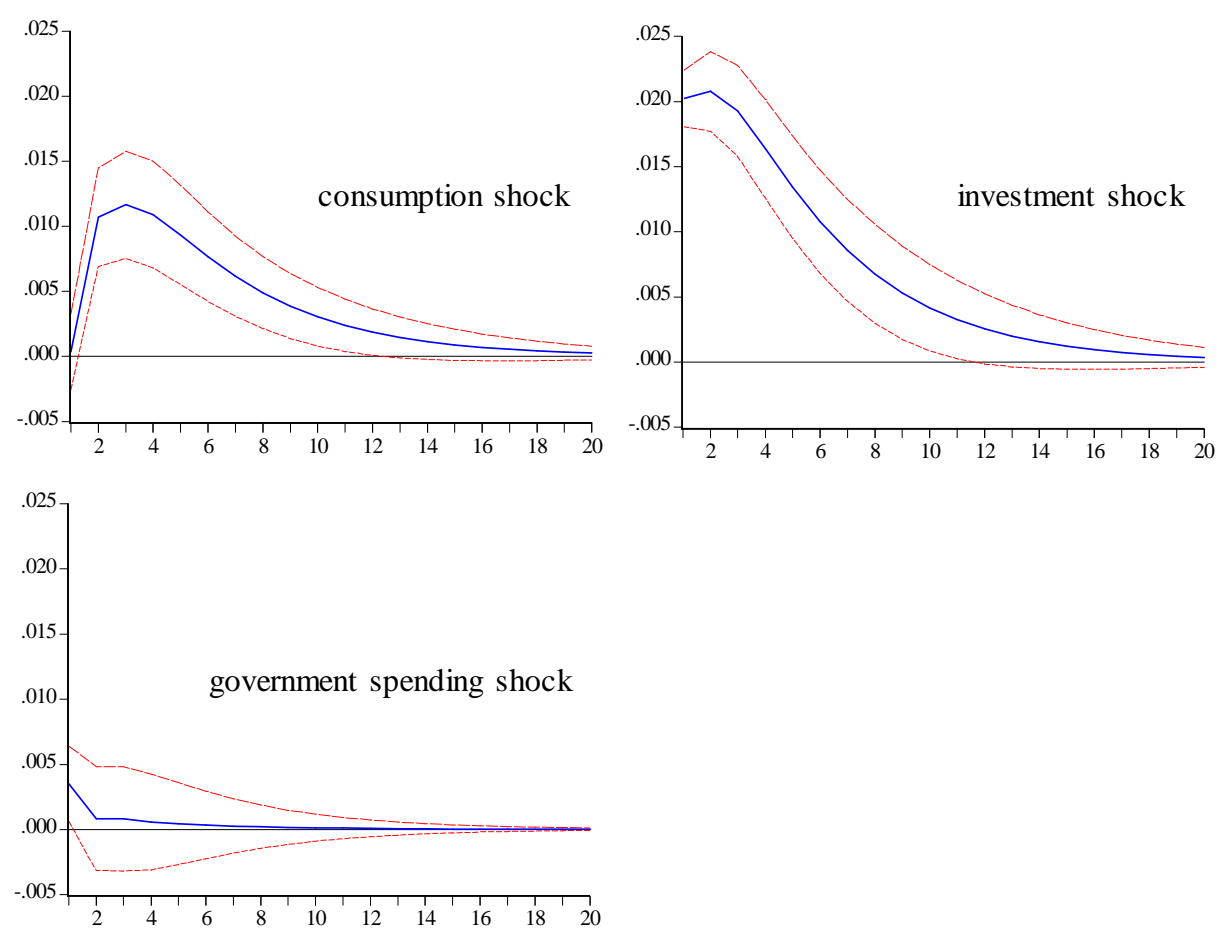

\section{Part B: Response of $\hat{u}_{t-1}^{M L}$ to impulses in select variables}
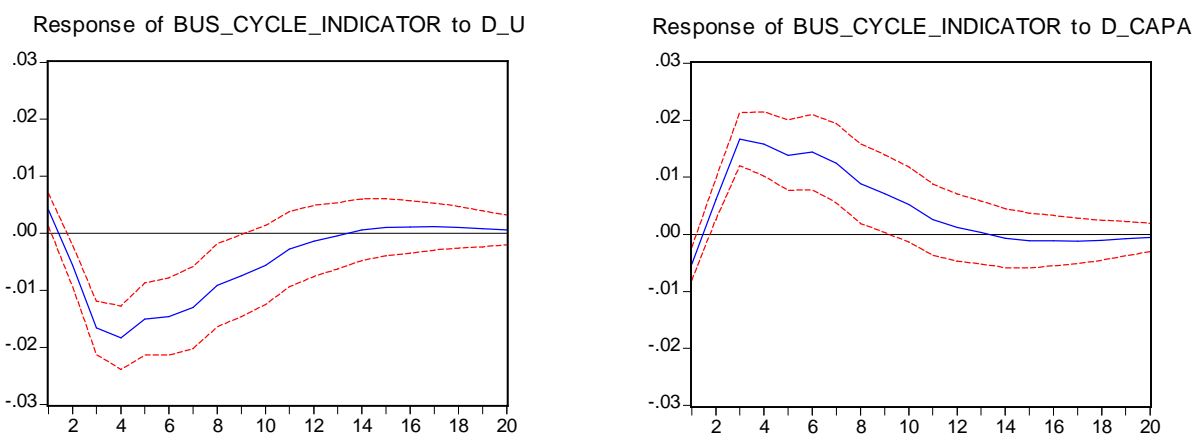

Response of BUS_CYCLE_INDICATOR to D_CPI_INFL

Response of BUS_CYCLE_INDICATOR to D_FEDFUNDS
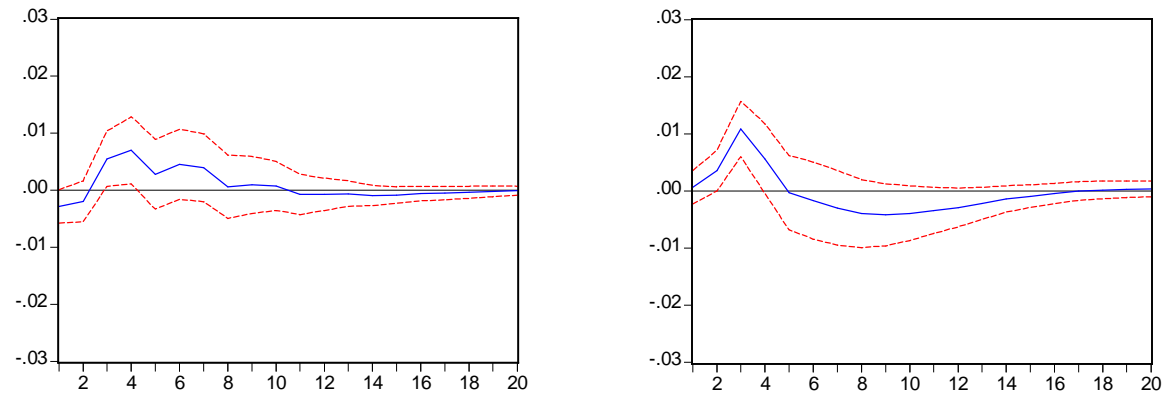
Part C: Full system impulse response functions
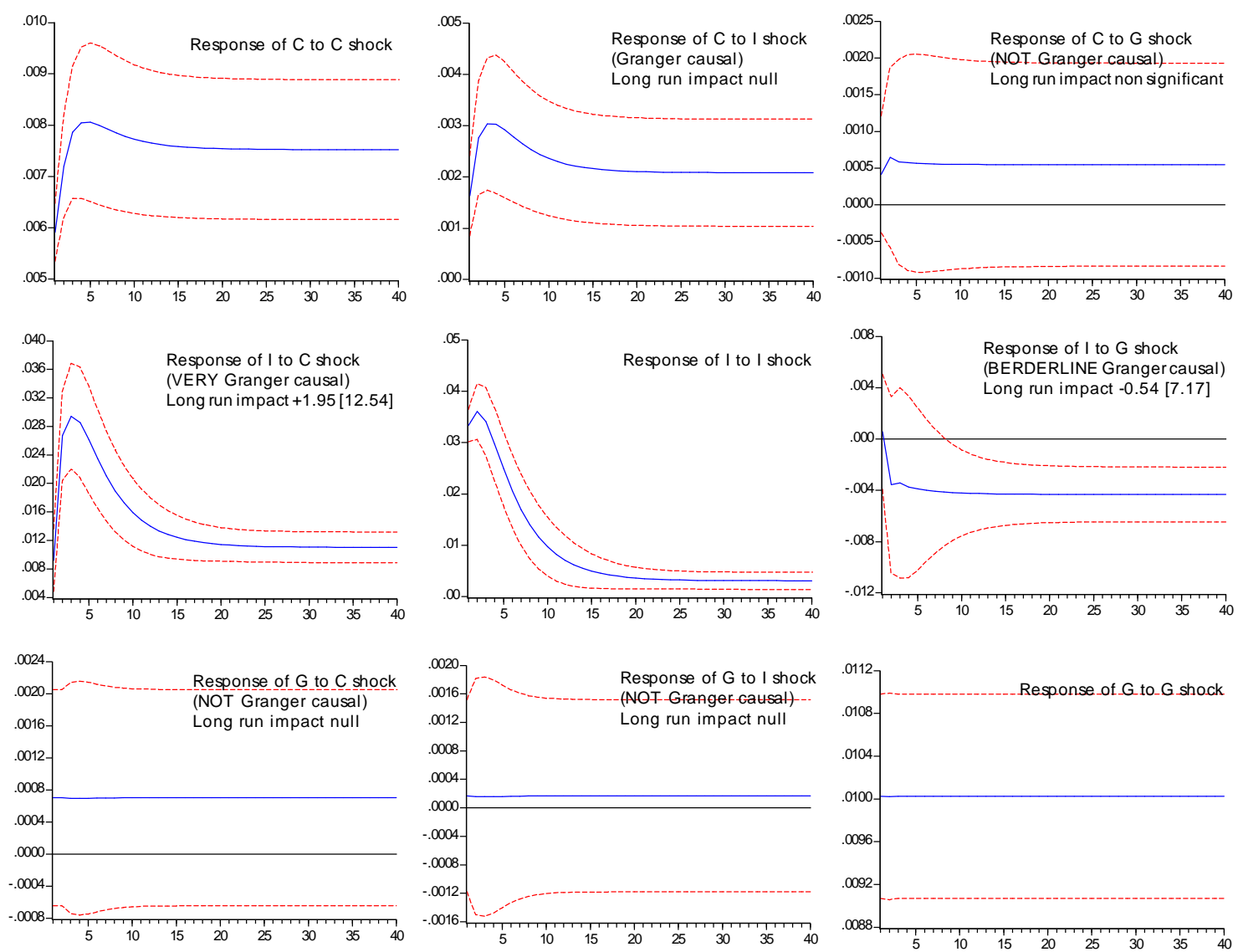

Note: The dashed lines represent the (asymptotic) 95-percent confidence bands of the generalized impulse-response functions (Pesaran and Shin 1998). The model is restricted by $H_{l}$ and $H_{2}$.

So, our estimated cointegrating relationship makes up for an investment-dominated business cycle. But are there any other variables besides those of the model that could explain the dynamics of our business cycle indicator? One such proposition was put forth by Shaikh and Moudud (2004), who use a cointegrating relationship to provide estimates of capacity utilization. This is an interesting idea in the present context, mostly because we have found the cointegrating relationship to be dominated by investment, and because what investment does is to build—or reduce, through depreciation—production capacity.

The meaning of the cointegrating relation was investigated further in the following way. A set of candidate variables was chosen (all are well-known indicators) and modeled with a classic stationary VAR along with the cointegrating relationship. In a general-to-specific fashion, the non-significant (in the sense of non-causal) variables for the cointegrating relationship were taken out of the model until only significant (causal) predictors remained. 
Causality was tested for with the usual Granger prediction test. The candidate variables are listed below, but because of the length of the procedure, the procedure details will be omitted here. $^{11}$

The iterative procedure found the following variables to be non-predictive, in turn, of the cointegrating relationship (at the 10-percent level): the T-Bill 3 months, the ECRI, the ISM, and the T-Bill 10 years. Those were sequentially taken out of the model so that only the changes in industrial capacity, the unemployment rate, the CPI inflation, and the Fed Funds remain. Each of these four variables was statistically significant at the 5-percent level, but the changes in industrial capacity came out significant at the $1 \%$ level. Altogether, the last estimated model is a VAR(3) model consisting of those four variables, explaining $\bar{R}^{2}=89 \%$ of the variance of our business cycle indicator, quite a good fit.

However, "significance of prediction" does not tell us how strong the impact is. A variable can be a good qualitative predictor but have a small-to-insignificant quantitative effect. The magnitude of impact was assessed by impulse-response functions, which are presented on Figure 4, Part B. The results indicate that the cointegrating relationship is negatively impacted by unemployment and positively impacted by industrial capacity. This result implies that a degradation of activity is associated with an acceleration of unemployment and a slowdown in industrial capacity, which conforms to common knowledge. On the other hand, changes in inflation and the Fed Funds rate, though significant predictors, are not found to have a significant quantitative impact on the business cycle indicator. ${ }^{12}$

Overall, our inquiry into the cointegration relationship provides empirical evidence that it represents more than just an "error term," as it is usually understood. The "error term" is very close to the business cycle and to a capacity effect in both labor and capital. Thus, the cointegrating relationship can be understood as a business cycle/capacity indicator. And, confirming something that may have been expected, this business cycle/capacity indicator is dominated by investment. However, the finding that part of the business cycle can be related to

\footnotetext{
${ }^{11}$ The candidates chosen were the change in the unemployment rate, the change in total industrial capacity, the changes in the inflation rate (CPI), the ISM manager's confidence index, the changes in ECRI's weekly leading index, the changes in the 10-year and 3-month Treasury Bill (constant maturity), and the changes in the Fed Funds rate. Although many other variables could be added, the present list presents the advantage of being sufficiently comprehensive for the purpose at hand. All eight variables are made stationary and the model has been estimated with the minimum lag length for which the errors are not autocorrelated, usually three quarters. Since data availability varies, the largest sample has always been used (starting in either 1955 or 1968).

${ }^{12}$ One possibility is that inflation and the Fed Funds evolve with the business cycle, rather than impacting it quantitatively.
} 
consumption is not trivial—and we now need to inquire more deeply into the role of this variable.

\section{SHORT-RUN AND LONG-RUN CAUSALITY AND A CONDITIONAL MODEL FOR INVESTMENT}

The interpretation of a cointegrating relationship is that of a long-run, steady-state relationship that shows no dynamics and no causality in itself. We now need to complement the previous section by analyzing the dynamic and causal properties of the model. So far, we have described investment as generating the business cycle and reducing/creating unused capacity. But is investment the initial causal factor? Again, this section provides the econometric background that will be re-interpreted along theoretical lines in Section 6.

We have already partly answered the question of causality in Section 3. The weak exogeneity tests indicated that consumption and government spending were (weakly) exogenous and that investment was endogenous. This implies that, over the long run, investment is not a causal factor since it reacts to changes in consumption and investment. This proposition can be further investigated using two other statistical tests. The first one is the usual Granger "causality" test which tests for significant precedence. As is well known, this test is a temporal causality test and, to the extent that only stationary terms enter the computation, Granger causality is better understood as a short-run causality test. The second test is to estimate the long-run impact matrix of shocks, $\mathrm{C}$ in Equation (3) above, and check which variables are significant causal factors.

Table 3 Granger causality tests

\begin{tabular}{|c|c|c|c|c|c|}
\hline & $\Delta \log C_{t-1}$ & $\Delta \log I_{t-1}$ & $\Delta \log G_{t-1}$ & Joint & $\begin{array}{l}\text { Note: weak } \\
\text { exogeneity }\end{array}$ \\
\hline$\Delta \log C_{t}$ & -- & $\begin{array}{c}\mathbf{0 . 0 2} \\
{[5.75]}\end{array}$ & $0.71 \quad[0.14]$ & $0.06 \quad[5.75]$ & $0.91 \quad[0.19]$ \\
\hline$\Delta \log I_{t}$ & $\begin{array}{c}\mathbf{0 . 0 0} \\
{[\mathbf{5 7 . 1 0}]}\end{array}$ & -- & $0.05 \quad[3.86]$ & $\begin{array}{c}\mathbf{0 . 0 0} \\
{[\mathbf{5 8 . 4 5}]}\end{array}$ & $\begin{array}{c}0.00 \\
{[29.72]}\end{array}$ \\
\hline$\Delta \log G_{t}$ & $0.68 \quad[0.17]$ & $0.73[0.12]$ & -- & $0.89[0.22]$ & $0.54 \quad[1.23]$ \\
\hline
\end{tabular}

Note: Causality runs from column to row (significant causal directions in bold). Reported statistics are probabilities of non-causality, with chi-square statistics in brackets, except for the last column, which reports the probabilities of $\alpha_{\mathrm{i}}=0$ with LR test statistics in brackets. 
The results of Granger causality tests are given in Table 3. There is a clear distinction between exogenous (causal) or endogenous (caused) variables in the model. By far, the Granger test points to investment as the most endogenous variable-we have induced investment.

Consumption comes next as a borderline case, while government spending turns out as the most exogenous variable of the model. The Granger causality results thus confirm the weak exogeneity tests. Combining those two tests, we find that government spending is exogenous in the short run and in the long run, making government spending strongly exogenous. ${ }^{13}$ This implies that one of the two common trends in the model is the level of government spending itself.

The effect of the stochastic shocks on the variables is summarized in $\mathrm{C}$, the long-run impact matrix of shocks. The estimated moving average representation is given in (4): ${ }^{14}$

$$
\left[\begin{array}{l}
\log C_{t} \\
\log I_{t} \\
\log G_{t}
\end{array}\right]=\left[\begin{array}{ccc}
+1.27 & 0 & 0^{n s} \\
{[12.54]} & & \\
+1.95 & 0 & -0.54 \\
{[12.54]} & & {[7.17]} \\
0 & 0 & 1
\end{array}\right]\left[\begin{array}{l}
\sum \varepsilon_{C, t} \\
\sum \varepsilon_{I, t} \\
\sum \varepsilon_{G, t}
\end{array}\right]+\left[\begin{array}{l}
0.009 \\
0.011 \\
0.004
\end{array}\right] t+C^{*}(L) \varepsilon_{t}+\tilde{X}_{0}
$$

The C matrix shows highly significant coefficients except for the effect of government spending on consumption. The matrix shows the long-run effects of the components of GDP on growth. Consumption shocks have the largest impact on the system, mostly on investment (+1.95). Investment is also found to respond negatively to the level of government spending, albeit the effect is four times smaller than that of consumption $(-0.54)$. The latter coefficient represents the long-run elasticity of investment to government spending. The negative sign is evidence of a crowding out effect, albeit of a small magnitude compared to the other elasticities captured in the $\mathrm{C}$ matrix. A plausible interpretation of the

\footnotetext{
${ }^{13}$ This means that the model's equation for government spending collapses to $\Delta \log G_{t}=\hat{\varepsilon}_{G, t}$ or, equivalently, government spending is the sum of random shocks such as $\log G_{t}=\sum \hat{\varepsilon}_{G, t}$

${ }^{14}$ The $\mathrm{C}$ matrix has been estimated after imposing a unit vector in the government spending line, a property the model should verify since government spending is strongly exogenous (Juselius 2006). This restriction could not be rejected at the 0.54 level. The (approximate, asymptotic) standard errors are given in brackets and are derived following Paruolo (1997). In addition, the C matrix features a zero column for investment shocks since those have been found to have only transitory (short-run) effects. Note, finally, that the deterministic trend coefficients are very close to the observed average (quarterly) growth rates of each variable, those being 0.87 percent, 1.10 percent, and 0.54 percent for consumption, investment, and government outlays, respectively.
} 
crowding out effect may lie in proactive policies. When investment falters, policymakers aim to restore activity by increasing government spending, making for a negative elasticity. The fullsystem impulse-response functions are reported in Figure 4, Part C.

Finally, a compact, "partial model” for investment can be estimated. Engle, Hendry, and Richard (1983) show that we can summarize the overall system by modeling the endogenous variable as conditioned (the econometric term) by the (weakly) exogenous variables. In the context of the results above, this translates into investment being conditioned by consumption and government spending. The estimated conditional model for investment is then given by the single equation $(7):{ }^{15}$

$$
\begin{aligned}
\Delta \log I_{t}= & -\underset{[5.84]}{0.26} \hat{u}_{t-1}^{M L}+\underset{[0.86]}{0.05} \Delta \log I_{t-1} \\
& +\underset{[7.07]}{2.63} \Delta \log C_{t-1}+\underset{[4.27]}{1.53} \Delta \log C_{t}-\underset{[2.26]}{0.49} \Delta \log G_{t-1}+\underset{[0.15]}{0.03} \Delta \log G_{t} \\
& +\underset{[4.89]}{0.12} D_{60 q 1 q 2}-\underset{[4.14]}{0.14} D_{75 q 1}-\underset{[4.01]}{0.13} D_{82 q 4}-\underset{[4.82]}{0.02}
\end{aligned}
$$

The precision of the fit $\left(\bar{R}^{2}=0.48\right)$ is fairly high given the well-known high volatility of investment, especially from one quarter to the next. What seems to matter the most for investment, both quantitatively and qualitatively (t-ratios in brackets), are consumption changes as well as the business cycle/capacity indicator, which both have the expected sign. In comparison, changes in government spending appear to have only a small, borderline significant effect on investment, which coincides with our previous Granger causality results.

\section{THEORETICAL REASSESSMENT AND CONCLUSIONS}

The present paper was concerned with the question of what has driven (realized) US output, aside from taxes and trade, in the postwar period, 1955-2007. The cointegrated VAR exercise has shown that, indeed, not all components of output have the same effects on the aggregate, nor do they have the same role. Our inquiry reignites the need to distinguish between long-run and

\footnotetext{
${ }^{15}$ Note that a partial model does not change the value of the likelihood so that the structural coefficients $\alpha, \beta$ and therefore $\hat{u}_{t-1}^{M L}$ are unchanged. Non significant dummy variables have been subsequently removed from the model, but no new ones were introduced.
} 
short-run influences when we talk about economic growth, but also and maybe more importantly when we talk about economic policies.

We find that long-run growth consists of consumption and government spending shocks. The consumption effect is more important for long-run growth, but government spending is still a significant and positive contributor. Increases in government spending and/or consumption shift the whole system upwards, towards a higher permanent output level, while decreases in those two variables shift the whole system downwards. The importance of government spending is seen through our estimate of the G-multiplier of 1.5, which is a permanent shock to the economy if everything else $(\mathrm{C}, \mathrm{I})$ is held constant. The magnitude of the government spending multiplier conforms to estimates arrived at by a wide range of authors and international organizations, although some economists find smaller (even negative!) multipliers.

On the other hand, we find investment to have only transitory effects on output, which is to say, increases in investment will only shift the system upward in the short run. While the econometric literature agrees on this last point, the idea of transitory investment shocks is at odds with the theoretical "investment-led conventional wisdom" that prevails when we deal with long-run growth. A few experiments allowed us to inquire more deeply into the role of investment, a question left aside in previous econometric investigations. Investment is found to behave according to older and well-respected theories: investment pertains to the business cycle (Tinbergen 1939), presents a capacity effect (Eisner 1963), and is induced (Samuelson 1939a, b). All of this implies that postwar American growth has been a mixture of consumption dynamism (mostly) and progressive government spending (moderately) in the long run, with investment under- and overreacting to the trend defined by the former variables.

\section{Induced Investment}

Perhaps the most interesting finding relates to the role of consumption. Consumption is the most causal variable, both quantitatively and qualitatively, for the system as a whole - and for investment in particular. This contradicts the investment-led theory, but this is understandable with reference to the principle of acceleration or "induced investment" (Samuelson 1939a, b). The idea is that investment is not undertaken for its own sake, but rather if some consumption demand is realized, or expected. 
Samuelson originally assumes that ${ }^{16}$

$$
\left\{\begin{array}{l}
C_{t}=a Y_{t-1} \\
I_{t}=b \Delta C_{t}
\end{array}\right.
$$

so that production can be rewritten as $Y_{t} \equiv a_{1} Y_{t-1}+a_{2} Y_{t-2}+a_{3}$. This equation presents obvious similarities with our model: the cointegrated VAR was shown to be most efficiently reduced to $\boldsymbol{X}_{t} \equiv \boldsymbol{A}_{1} \boldsymbol{X}_{t-1}+\boldsymbol{A}_{2} \boldsymbol{X}_{t-2}+\boldsymbol{A}_{3}+\varepsilon_{t}$. The formulations look the same but there are important differences:

i. Samuelson's approach is deterministic, or "algebraic," while ours is stochastic. Samuelson's accelerator involves coefficients (scalars), while the cointegrated VAR coefficients $\mathbf{A}_{\mathbf{i}}$ are freely estimated matrices.

ii. Samuelson's model assumes such equations, while we provide empirical evidence allowing for a reduction of a general model to the same structural equation(s). Our approach starts from a more general framework, which is reduced to Samuelson's case by a series of successful statistical tests.

iii. In particular, Samuelson assumes "induced" investment, and we provide several econometric results supporting this claim. The econometric terminology is that investment is "conditioned" by consumption and government spending.

iv. Samuelson finds a hump-shaped response of investment and we do corroborate this finding. ${ }^{17}$ We showed that the hump-shaped response of output is, indeed, related to investment's propensity to overshoot—-thus generating the business cycle. In Samuelson (1939a), the hump-shaped response of output originates from a compounding-output exercise first initiated by an increase of government spending. We find confirmation that such a starting point makes sense in the strong exogeneity of government spending.

In addition to Samuelson and Tinbergen, our findings provide substantial parallels with the works of Eisner $(1960,1963,1967$, and 1978) on the investment function. In those early econometric studies, Eisner finds, indeed, that the "principle of acceleration" is a very strong and very significant predictor of individual companies' investment plans. ${ }^{18}$

\footnotetext{
${ }^{16}$ Later reformulations and extensions by different authors, although more complete, do not change the main idea presented here.

${ }^{17}$ We provided statistical evidence for a VAR(2) and one feature of such a model is that hump-shaped response of output to shocks is an indication of the principle of acceleration at work (Blanchard 1993).

${ }^{18}$ Eisner $(1963,1967)$ finds little evidence of investment being driven by profits, a point also made in Giovannoni and Parguez (2007).
} 
But there is more. In those works, Eisner takes up Friedman's (1957) idea of permanent income to apply it to investment. The central proposition of the "permanent theory of investment," as Eisner calls it, is that investment will simply not be undertaken if only a temporary increase in total income is expected. Eisner $(1967,1978)$ provides empirical evidence for such a claim, based on the study of the investment decisions of 800 firms. He finds that investment plans depend on a variety of factors but most crucially indeed upon expected future sales/earnings. Thus, Eisner concludes that investment spending depends on the predictability of earnings.

To some extent, our findings can be interpreted along such a "permanent income theory of investment." We do find that investment is induced and that consumption (sales) is the variable that matters the most. We do also find that consumption and government spending are exogenous and behaving smoothly, which helps make sales (output) more predictable.

\section{Stabilization Policy}

This leads us to a characterization of the third variable, government spending. In this respect, we go further than Samuelson (1939a, b), who assumed for simplification that government spending is constant. To the contrary, we allow for variable government spending and find it to be the most exogenous variable, more than consumption and definitely more than investment. Several scenarios can be considered.

In the spirit of our results, John Kenneth Galbraith $(1958,1967)$ is quite possibly the reference to mention regarding the importance of government spending. In those two books, Galbraith famously stresses the paramount role of consumption, both for better and worst. But in times of private excesses, Galbraith argues, public spending should receive all the focus necessary to maintain a good balance of powers. Galbraith sees in the government a (potentially) profoundly stabilizing force, as did Keynes, of course. ${ }^{19}$ Our estimates indicate that government spending does not, indeed, contradict consumption expansion and, to the contrary, that consumption and government spending do go hand-in-hand in defining long-run growth. ${ }^{20}$ The "stabilization effect" of government spending is echoed by our finding of strong exogeneity and by the permanent multiplier effect of about 1.5 .

\footnotetext{
19 The converse proposition has been put forth recently by Galbraith (2008) who has shown recently that a government hijacked by private interests can be a profoundly destabilizing force-a "predator" for a country.

${ }^{20}$ Note that Galbraith was anticipating the developments in endogenous growth theory (Romer 1986), which also stress the importance of public spending. Substantial conceptual differences remain, however.
} 
Finally, it is worth investigating the relationship between government spending and investment. We need to relate the finding that investment merely describes the business cycle and that government spending has virtually zero effect on investment over the short run, while a small crowding out effect shows up over the longer run. If all of this is correct, two conclusions emerge.

The first is that typical government spending does not influence the business cycle (over the short run.) This can only be true if government spending consists mostly of exogenous (or routine, or "structural") types of outlays, as opposed to cyclical ones. ${ }^{21}$ This could be taken as contradicting the view held by Keynesian economists that government spending has been effective in the short-run battle against recessions. However, this is not necessarily so: maybe the government spending cure has simply not been tried on a sufficient magnitude. Brown (1956) famously found, indeed, that fiscal policy had not been effective during the 1930s simply because it had not been tried. Note, also, that our 1955-2007 sample also contains the "great moderation" period in which recessions were mostly fought not by government spending, but by tax cuts.

Second, we have the result of a crowding out effect that materializes over the long run; yet investment is cyclical. This could mean that the crowding out effect may not so much lead to a lower investment level, as it does to a smaller investment overshooting. If this is correct, government spending could be expected to reduce the amplitude of the business cycle and to increase overall economic stability. Such a "stabilizing" characterization of government spending would explain why the countries of Continental Europe, which have higher levels of government spending, experience moderate cycles as compared to the US.

\section{Policy Implications and the Current Recession}

Finally, it is tempting to make a short comment addressing the current economic crisis in light of our results. Such a comparison should be careful, if only because our model only describes average past behavior, while "this time is different." However, we will argue that our findings point to a general understanding of growth to which the current crisis does not make exception-only on a different scale and with some specifics.

\footnotetext{
${ }^{21}$ In the postwar United States, most turning points took place following tax cuts and not so much because of changes in government spending. A deeper look at the role of taxes is left to future work.
} 
The current downturn is characterized by a sharp fall of investment, which confirms our result that business cycles are investment-dominated. Residential investment increased faster than GDP for some time, but eventually the bubble burst. Following our results, the problem was that the last expansion was based on a variable_-private investment-which is so cyclical. The mistake was to take investment as a trend-variable rather than really a cycle-variable. Doing so and, even worse, promoting so through loose (or inexistent) regulation, is bound to lead to unstable growth and the formation of bubbles. ${ }^{22}$ Investment is intrinsically unstable, unless it is managed or regulated.

The bubble burst in the subprime sector because those households-those consumershad the weakest balance sheets. This is, again, the principle of induced investment we identified, but working backward: the failure of consumers' (households') demand led to reduced investment. With investment being induced by consumption and consumption being limited by damaged balance sheets and unemployment, one should not place too much confidence in an investment-led recovery. Until household demand resumes, investment and the economy will simply stagnate at whatever low level of economic activity clears inventories. Because the crisis struck at the core and because of its magnitude, the recovery is likely to be slow, and has proven to be slow four years into the crisis.

The impossible likelihood of consumption—or investment-led recoveries—makes a stronger case for a policy-led recovery. Managing and re-regulating investment seems crucial to avoid future crises; proactive fiscal and monetary policies are necessary to get out of the crisis as soon as possible and avoid waste. Our results indicate that the latter policies would be more effective in the long run if they are aimed at restoring households' balance sheets, as opposed to fostering another short-lived investment-led expansion.

The last area to work out, of course, concerns precisely which long-term policies to undertake, what magnitude, and for how long.

\footnotetext{
${ }^{22}$ The tech boom of the late 1990 s is another example of investment-driven boom-and-bust.
} 


\section{REFERENCES}

Beveridge S. and C. Nelson. 1981. "A New Approach to Decomposition of Economic Time Series into Permanent and Transitory Components with Particular Attention to

Measurement of the Business Cycle." Journal of Monetary Economics 7(2): 151-174.

Blanchard, O. 1993. "Consumption and the Recession of 1990-1991." American Economic

Review, Papers and Proceedings of the Hundred and Fifth Annual Meeting of the American Economic Association 83(2): 270-274.

Brüggeman R., H. Lütkepohl, and P. Saikkonen. 2006. "Residual Autocorrelation Testing for Vector Error Correction Models.” Journal of Econometrics 134: 579-604.

Bureau of Economic Analysis. 2012. National Income and Products Accounts. Available online at: http://www.bea.gov/national/.

Cochrane, J. 1994. "Permanent and Transitory Components of GNP and Stock Prices." Quarterly Journal of Economics 109: 241-265.

Brown, E. C. 1956. "Fiscal Policy in the Thirties: A Reappraisal" American Economic Review 46: 857-79.

Eisner, R. 1960. “A Distributed Lag Investment Function.” Econometrica 28(1): 1-29.

. 1963. "Investment: Fact and Fancy." The American Economic Review 53(2): 237-246.

. 1967. "A Permanent Income Theory for Investment: Some Empirical Explorations."

The American Economic Review 57(3): 363-390.

- 1978. Factors in Business Investment. Cambridge, MA: Ballinger.

Engle, R. and C. Granger. 1987. "Co-integration and Error Correction: Representation, Estimation, and Testing." Econometrica 55: 251-276.

Engle R., D. Hendry, and J-F. Richard. 1983. "Exogeneity.” Econometrica 51(2) 277-304.

Fama E. 1992. "Transitory Variation in Investment and Output." Journal of Monetary Economics 30: 467-480.

Fisher, L., H. Huh, and E. Tallman. 2003. "Permanent Income and Transitory Variation in Investment and Output.” Journal of Macroeconomics 25: 149-168.

Friedman, M. 1957. A Theory of the Consumption Function. Princeton, NJ: Princeton University Press.

Galbraith, J. K. 2008. The Predator State: How Conservatives abandoned the Free Market and why Liberals Should Too. New York: The Free Press.

- (1958) 1998. The Affluent Society, 40 ${ }^{\text {th }}$ anniversary edition. New York, NY: Mariner Books: A Houghton Mifflin Company, . (1967) 2007. The New Industrial State. The James Madison Library in American Politics, Princeton, NJ: Princeton University Press.

Giovannoni, O. and A. Parguez. 2007. What Drives Profits? In E. Hein and A. Truger (Eds.), Macroeconomics and Macroeconomic Policies. London: Edward Elgar. 
Hansen H. and S. Johansen. 1999. "Some Tests for Parameter Constancy in Cointegrated VAR Models.” Econometrics Journal 2: 306-333.

Johansen, S. 1988. "Statistical Analysis of Cointegration Vectors." Journal of Economic Dynamics and Control 12: 2-3, 231-254.

- 1991. "Estimation and Hypothesis Testing of Cointegration Vectors in Gaussian Vector Autoregressive Models." Econometrica 59: 1551-1580.

- 1992. "Testing Weak Exogeneity and the Order of Cointegration in UK Money Demand." Journal of Policy Modelling 14: 313-334.

-1996. Likelihood-Based Inference in Cointegrated Vector Autoregressive Models. $2^{\text {nd }}$ Ed. Oxford: Oxford University Press.

- 2002. "A Small Sample Correction of the Test for Cointegrating Rank in the Vector Autoregressive Model.” Econometrica 70: 1929-1961.

Johansen, S. and K. Juselius. 1990. "Maximum Likelihood Estimation and Inference on Cointegration - with Applications to the Demand for Money." Oxford Bulletin of Economics and Statistics 52: 169-210.

- 1992. "Structural Tests in a Multivariate Cointegration Analysis of the PPP and UIP for UK.” Journal of Econometrics 53: 211-244.

Juselius, K. 2006. The Cointegrated VAR Model - Methodology and Applications. Oxford: Oxford University Press.

Keynes, J. M. (1936) 1997. The General Theory of Employment, Interest, and Money. New York: Prometheus Books.

King R., C. Plosser, J. Stock, and M. Watson. 1991. "Stochastic Trends and Economic Fluctuations." American Economic Review 81: 819-840.

Paruolo, P. 1997. "Asymptotic Inference on the Moving Average Impact Matrix in Cointegrated I(1) Systems." Econometric Theory 13: 79-118.

Pesaran, M. and Y. Shin. 1998. "Impulse Response Analysis in Linear Multivariate Models." Economics Letters 58: 17-29.

Rahbek, A., E. Hansen, and J. Dennis. 2002. "ARCH Innovations and their Impact on Cointegration Rank Testing." Copenhagen, Denmark: Department of Statistics and Operations Research, University of Copenhagen.

Romer, P. 1986. "Increasing Returns and Long-Run Growth.” Journal of Political Economy 94(5): 1002-1037.

Saikkonen, P. and H. Lütkepohl. 2000a. "Testing for the Cointegrating Rank of a VAR Process with an Intercept." Econometric Theory 16: 373-406.

- 2000b. "Testing for the Cointegrating Rank of a VAR Process with Structural Shifts." Journal of Business \& Economic Statistics 18: 451-464.

—. 2000c. "Trend Adjustment Prior to Testing for the Cointegrating Rank of a Vector Autoregressive Process.” Journal of Time Series Analysis 21: 435-456. 
Samuelson, P. 1939a. "Interactions between the Multiplier Analysis and the Principle of Acceleration." Review of Economic Statistics 21(2): 75-78.

. 1939b. "A Synthesis of the Principle of Acceleration and the Multiplier." Journal of Political Economy 47(6): 786-797.

Shaikh, A. and J. Moudud. 2004. "Measuring Capacity Utilization in OECD Countries: A Cointegration Method.” Working Paper 415. Annandale-on-Hudson, NY: Levy Economics Institute of Bard College.

Solow, R. 1956. "A Contribution to the Theory of Economic Growth." Quarterly Journal of Economics 70(1): 65-94.

- 1957. "Technical Change and the Aggregate Production Function." The Review of Economics and Statistics 39(3): 312-320.

Sims, C. 1980. "Macroeconomics and Reality." Econometrica 48(1): 1-48.

Tinbergen, J. 1938. "Statistical Evidence on the Acceleration Principle." Economica 5(18): 164176.

1939. Statistical Testing of Business-Cycle Theories, Vols. I and II. Geneva: League of Nations. 


\section{APPENDIX}

Both Johansen (1996) and Juselius (2006) stress the importance of a carefully specified model (1). This implies deciding upon the lag length $k$ and the location of the potentially relevant dummies $D_{t}$ simultaneously before checking for Gaussian errors. Given that those parameters have to be jointly chosen, I used the following incremental procedure:

1. Estimate the model starting with $k=1$.

2. Check for abnormal pikes in the residuals and introduce the relevant dummies. A criterion for selecting "large" outliers can be set at $\left|\hat{v}_{i t}\right|>3.3 \hat{\sigma}_{\hat{v}_{i t}}$, so that only observations producing residuals significant at the $1 \%$ level would be explicitly accounted for. Ideally, dummies should represent purely exogenous shocks.

3. Test for Gaussian residuals. Brüggeman, Lütkepohl, and Saikkonen (2006) recommend the use of the Breush-Godfrey LM test when investigating low-order autocorrelation in a small system with a large sample, as is the case here. Juselius (2006) suggests that absence of normality is not so much of a problem when it originates from excess kurtosis as it is from excess skewness (hence the importance of introducing relevant dummies). Rahbek, Hansen, and Dennis (2002) find that cointegration tests are quite robust to moderate heteroskedasticity in the residuals.

4. Perform stability tests on the reduced form (1).

5. If the residuals are not Gaussian or if the model is not stable, restart at step 1 with $k=k+1$. When this is done the error-correction form (2) can be estimated.

6. Perform the cointegration tests to choose the rank $r$; check alternatives.

7. Check the largest non-unit root and the significance of the long-run deterministic terms.

8. Identify the long-run structure $\beta$ and impose restrictions on $\alpha, \beta$

This procedure should lead to a parsimonious and stable model accounting for outliers in which inference makes sense.

This specification procedure was applied to our model of consumption, investment, and government spending for the period 1955q1-2007q4. As a preliminary analysis, we ran system reduction tests and looked at the values of some usual information criteria. The results, presented in Tables A1 and A2, indicate the choice $k=2$ as appropriate. This was confirmed by the above procedure, which failed to find Gaussian residuals for $k=1$, even after the introduction 
of dummies. For $k=2$, the criteria $\left|\hat{u}_{i t}\right|>3.3 \hat{\sigma}_{\hat{u}_{i t}}$ revealed seven outliers in the residuals, which are listed and interpreted in Table A3.

Table Al Lag length determination (System reduction tests)

\begin{tabular}{lll|ll}
$p(\operatorname{VAR}(4)$ & $<<\operatorname{VAR}(5))=0.03$ & {$[18.08]$} & $\boldsymbol{p}(\operatorname{VAR}(2)<<\operatorname{VAR}(3))=\mathbf{0 . 0 9}$ & {$\left[\mathbf{1 4 . 9}^{\dagger}\right]$} \\
$p(\operatorname{VAR}(3)<<\operatorname{VAR}(5))=0.00$ & {$[39.14]$} & $p(\operatorname{VAR}(1)<<\operatorname{VAR}(5))=0.00$ & {$[124.4]$} \\
$p(\operatorname{VAR}(3)<<\operatorname{VAR}(4))=0.01$ & {$[21.07]$} & $p(\operatorname{VAR}(1)<<\operatorname{VAR}(4))=0.00$ & {$[106.3]$} \\
$p(\operatorname{VAR}(2)<<\operatorname{VAR}(5))=0.00$ & {$[54.04]$} & $p(\operatorname{VAR}(1)<<\operatorname{VAR}(3))=0.00$ & {$[85.21]$} \\
$p(\operatorname{VAR}(2)<<\operatorname{VAR}(4))=0.01$ & {$[35.96]$} & $p(\operatorname{VAR}(1)<<\operatorname{VAR}(2))=0.00$ & {$[70.32]$}
\end{tabular}

Note: Statistics reported are probabilities, with chi-square statistics reported in brackets.

${ }^{\dagger}$ Minimum test value

Table A2 Information criteria

\begin{tabular}{c|cccc} 
& FPE & AIC & SIC & HQ \\
\hline$k=1$ & $6.68 \mathrm{e}-12$ & -17.22 & -16.69 & -17.01 \\
$k=2$ & $5.08 \mathrm{e}-12$ & -17.49 & $-\mathbf{1 6 . 8 3}^{\dagger}$ & $\mathbf{- 1 7 . 2 2}^{\dagger}$ \\
$k=3$ & $5.16 \mathrm{e}-12$ & -17.48 & -16.67 & -17.15 \\
$k=4$ & $5.05 \mathrm{e}-12$ & -17.50 & -16.55 & -17.11 \\
$k=5$ & $\mathbf{5 . 0 2 e - 1 2}$ & $\mathbf{- 1 7 . 5 1 ^ { \dagger }}$ & -16.41 & -17.06
\end{tabular}

${ }^{\dagger}$ Minimum test value

Table A3 Dummy location and interpretation

\begin{tabular}{l|c|l} 
Date & Equation & Tentative interpretation \\
\hline $\mathbf{1 9 6 0 q 1 q 2}$ & $I$ & Instability / Data problem? \\
\hline $\mathbf{1 9 6 3 q 3}$ & $G$ & Government spending shock (mostly nondefense) \\
\hline $\mathbf{1 9 6 7 q 1}$ & $G$ & Government spending shock (mostly defense) \\
\hline $\mathbf{1 9 7 4 q 4}$ & $C$ & Delayed oil shock effects? \\
$\mathbf{1 9 7 5 q 1}$ & $I$ & Credit controls, interest rate shock (-6 points) \\
\hline $\mathbf{1 9 8 0 q 2}$ & $C$ & Ind \\
\hline $\mathbf{1 9 8 2 q 4}$ & $I$ & Interest rate shock (-3 points in previous quarter)
\end{tabular}

Note: 1960q1q2 represents a transitional dummy variable (-1/+1) intended to account for two large residuals that have roughly the same size but opposite signs (this may be a data problem). The remaining dummy variables are the traditional "blip" dummies. Two additional large outliers in 1958q1 and 1971q1, mainly affecting investment, have not been included in the model, as those dates corresponding to business cycle turning points are more likely to be related to endogenous events rather than to exogenous events.

Table A4 Significance of dummy variables

\begin{tabular}{l|c|c|c|c}
\multirow{2}{*}{ Date } & found & \multicolumn{3}{|c}{ Coefficient and significance level in... } \\
& in equation & $\Delta \log C_{t}$ & $\Delta \log I_{t}$ & $\Delta \log G_{t}$ \\
\hline $\mathbf{1 9 6 0 q 1 q 2}$ & $I$ & $n . s$. & $+0.116^{* * * *}$ & $\mathbf{- 0 . 0 1 4 * *}$ \\
\hline $\mathbf{1 9 6 3 q 3}$ & $G$ & $n . s$. & $n . s$. & $\mathbf{+ 0 . 0 3 7 * * * *}$ \\
\hline $\mathbf{1 9 6 7 q 1}$ & $G$ & $n . s$. & $n . s$. & $\mathbf{+ 0 . 0 3 5 * * * *}$ \\
\hline $\mathbf{1 9 7 4 q 4}$ & $C$ & $-0.021^{* * * *}$ & $n . s$. & $n . s$. \\
$\mathbf{1 9 7 5 q 1}$ & $I$ & $n . s$. & $-0.137^{* * * *}$ & $n . s$. \\
\hline $\mathbf{1 9 8 0 q 2}$ & $C$ & $-0.029^{* * * *}$ & $-0.066^{* * *}$ & $n . s$. \\
\hline $\mathbf{1 9 8 2 q 4}$ & $I$ & $\mathbf{+ 0 . 0 1 0 *}$ & $\mathbf{- 0 . 1 2 0 * * * *}$ & $n . s$.
\end{tabular}

Note: $* * *, * * *$, and $* * * *$ represent significance at the $10 \%, 5 \%, 1 \%$, and $1 \%$ level, n.s. indicates non-significance at the $10 \%$ level. 
Figure Al Rank stability, fully estimated model

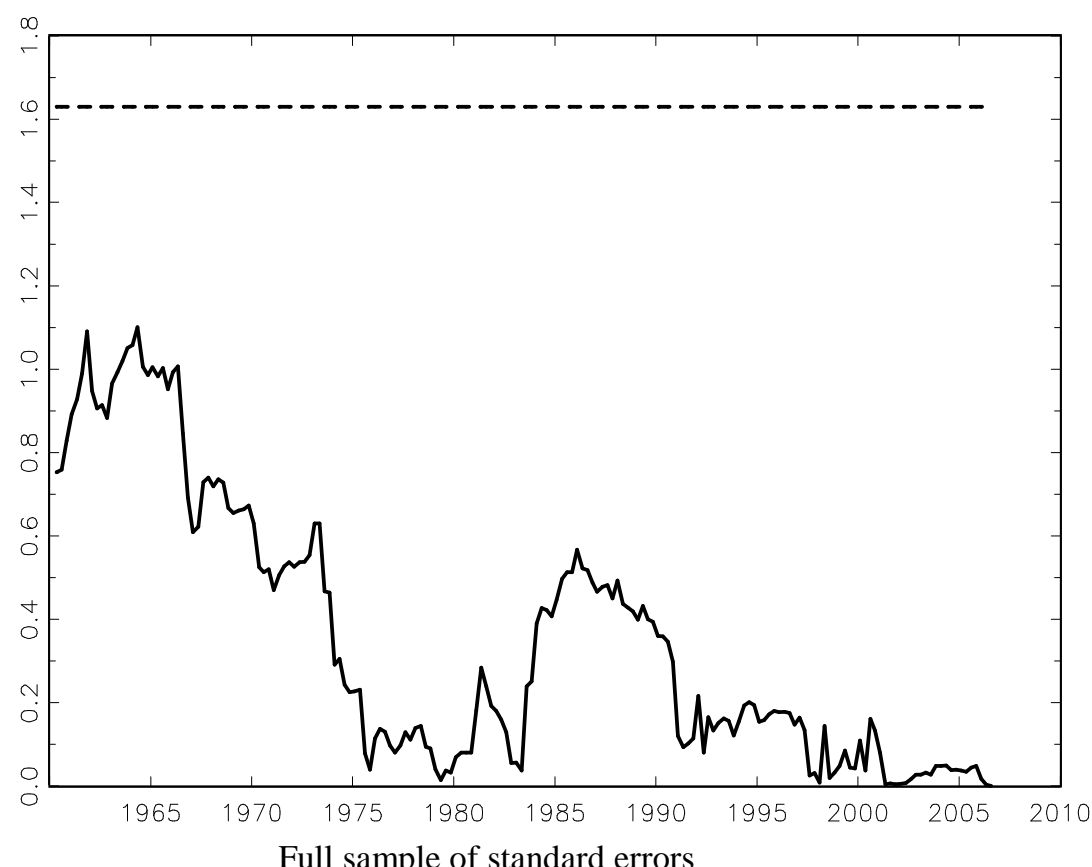

Full sample of standard errors

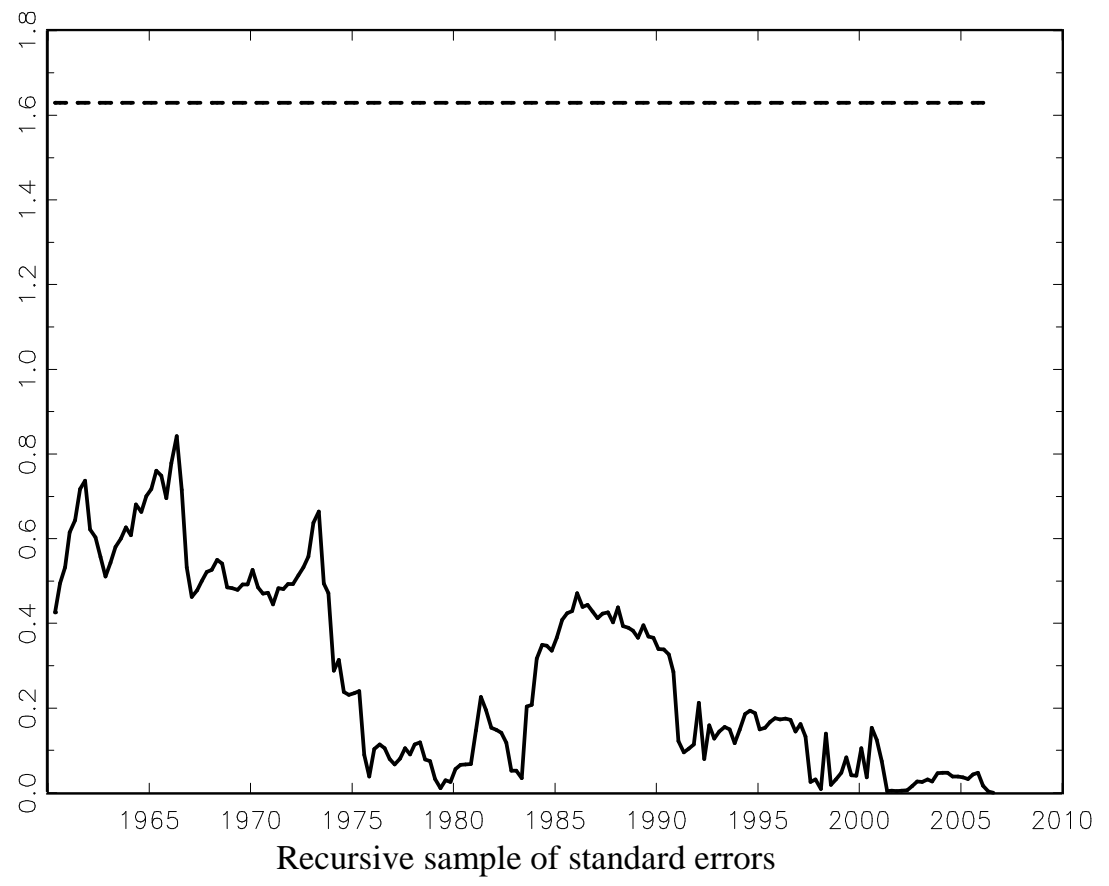

Note: Hansen and Johansen (1999) recursive eigenvalues test. All parameters are recursively estimated (X-form); the horizontal line represents the $1 \%$ critical value. 